\title{
A AMPLIACÃO DOS LIMITES SUBJETIVOS DA COISA JULGADA NO ÂMBITO DAS ACÕES COLETIVAS COMO INSTRUMENTO DE EFETIVACÃO DE DIREITOS FUNDAMENTAIS
}

THE EXTENSION OF THE SUBJECTIVE LIMITS OF RES JUDICATA IN THE CONTEXT OF CLASS ACTIONS AS A MEANS OF ENFORCING FUNDAMENTAL RIGHTS

\section{LA AMPLIACIÓN DE LOS LÍMITES SUBJETIVOS DE LA COSA JUZGADA EN EL ÁMBITO DE LAS DEMANDAS COLECTIVAS COMO INSTRUMENTO PARA HACER EFECTIVOS LOS DERECHOS FUNDAMENTALES}

Jaqueline Mielke Silva ${ }^{1}$

\section{RESUMO}

\begin{abstract}
A redação atual do artigo 16 da Lei da Ação Civil Pública (LACP) restringe os limites subjetivos da coisa julgada à competência do magistrado que julga a demanda de natureza coletiva. A vinculação da coisa julgada à competência territorial do julgador reflete a inadequação da dogmática jurídica para resolver os problemas decorrentes da transmodernidade. A dogmática jurídica precisa ser redimensionada de forma que o processo possa ser um instrumento de transformação da realidade social, a fim de ser alcançada a tão almejada justiça. Neste contexto, inconstitucional se revela o artigo 16 da LACP. Primeiro, porque restringe a efetivação de direitos fundamentais. Segundo, em razão de reduzir abrangência do instituto da coisa julgada prevista no artigo 5. , inciso XXXVI, da Constituição Federal. Terceiro, porque viola o princípio da isonomia. Quarto, porque a restrição territorial faz com que o número de demandas judiciais aumente, o que contraria o escopo do processo civil contemporâneo. Assim, os limites subjetivos da coisa julgada no âmbito coletivo devem ser (re) dimensionados de modo a assegurar de forma ampla a tutela de direitos fundamentais.
\end{abstract}

PALAVRAS-ChAVE: Coisa julgada. Limites subjetivos. Demanda coletiva. Direitos fundamentais. Transmodernidade.

\section{ABSTRACT}

The current wording of article 16 of the Public Civil Action Law (LACP) restricts the subjective limits of res judicata to the jurisdiction of the magistrate, who judges the action collectively. The link between res judicata and the territorial jurisdiction of the judge reflects the inadequacy of the legal dogma in resolving the recurrent problems of transmodernity. In this respect, article 16 of the LACP is shown to be unconstitutional. First, because it restricts the enforcement of fundamental rights. Second, because it reduces the scope of res judicata stipulated in article 5, paragraph 26, of the Federal Constitution. Third, because it violates the principal of equality. Fourth, because the territorial restriction increases the number of lawsuits, which contradicts the scope of contemporary civil procedure. Hence, the subjective limits of res judicata under the collective framework must be (re)shaped so as to ensure broader protection of fundamental rights.

1 Doutora e Mestre em Direito pela Universidade do Vale do Rio dos Sinos (UNISINOS). Especialista em Direito Processual Civil pela Pontifícia Universidade Católica do Rio Grande do Sul (PUC/RS), Professora de Direito Processual Civil na Faculdade Meridional (IMED), Faculdade INEDI, Escola Superior da Magistratura Federal (ESMAFE), Escola Superior da Magistratura do RS (AJURIS), Fundação Escola Superior do Ministério Público do RS (FMP), Fundação Escola Superior da Magistratura do Trabalho (FEMARGS). Sócia de Mielke e Lucena Advogados. 
KEYWORDS: Res judicata. Subjective limits. Class actions. Fundamental rights. Transmodernity.

RESUMEN

La redacción del actual artículo 16 de la Ley de la Acción Civil Pública -LACP- restringe los límites subjetivos de la cosa juzgada a la competencia del juez que examina la demanda de naturaleza colectiva. La vinculación de la cosa juzgada a la competencia territorial de aquel que juzga refleja la no adecuación de la dogmática jurídica para resolver los problemas derivados de la transmodernidad. La dogmática jurídica necesita ser redimensionada de manera que el proceso pueda ser un instrumento de transformación de la realidad social, a fin de que la tan deseada justicia pueda ser alcanzada. En tal contexto es inconstitucional el artículo 16 de la LACP. Primero, porque limita la efectividad de los derechos fundamentales. Segundo, porque reduce la amplitud del instituto de la cosa juzgada prevista en el artículo $5^{\circ}$, inciso XXXVI, de la Constitución Federal. Tercero, porque hiere el principio de la igualdad. Cuarto, porque la limitación territorial hace que la cantidad de demandas judiciales aumente, lo cual contradice el objeto del proceso civil contemporáneo. Así, los límites subjetivos de la cosa juzgada en el ámbito colectivo deben ser (re) dimensionados para garantizar ampliamente la tutela de los derechos fundamentales.

PALABRAS ClAVE: Cosa juzgada. Límites subjetivos. Demanda colectiva. Derechos fundamentales. Transmodernidad.

\section{AÇÃO CIVIL PÚBLICA COMO INSTRUMENTO DE PROTEÇÃO DOS INTERESSES TRANSINDIVIDUAIS}

\section{INTERESSES TRANSINDIVIDUAIS: UMA DECORRÊNCIA DO ESTADO SOCIAL E DEMOCRÁTICO DE DIREITO}

Os interesses transindividuais são fruto das modificações ocorridas no modelo liberal/ individualista de Estado². Ou seja: com a superação desse modelo - por meio do Estado Social e Democrático de Direito ${ }^{3}$ - houve uma verdadeira revolução em termos de categorias, direitos e de meios de proteção aos mesmos ${ }^{4}$.

Tais direitos ${ }^{5}$, além de evidentemente escaparem à tradição liberal/individualista, colocam-se como indispensáveis à sobrevivência contemporânea ${ }^{6}$. Trata-se de direitos que atingem toda a

2 No seu nascedouro, o Estado de Direito emerge aliado ao conteúdo do próprio liberalismo. Assim, os liames jurídicos do Estado têm relação direta com a concreção do ideário liberal no que diz respeito ao princípio da legalidade (submissão do poder estatal à lei, divisão de poderes e garantia de direitos individuais).

3 Segundo Manuel García Pelayo, "en términos generales, el Estado social significa históricamente el intento de adaptación del Estado tradicional (por el que entendemos en este caso el Estado Liberal burgués) a las condiciones sociales de la civilización industrial y posindustrial con sus nuevos y complejos problemas, pero también con sus grandes posibilidades técnicas, económicas y organizativas para enfrentarlos". Las transformaciones del Estado contemporaneo, p. 14 e 15".

4 A consagração dos direitos sociais não é uma descoberta do século XX, na exata medida em que as Declarações de Direitos da Revolução Francesa já estabeleciam obrigações positivas do Estado nos domínios do ensino e da assistência social, o que viria a ser aprofundado nas constituições do século XIX.

5 Cf. Mauro Cappelletti, refere, ao tratar do assunto, "que no campo jurídico o Estado Social incorporou novos direitos das mais variadas ordens, "direitos sociais dos pobres, os direitos sociais dos trabalhadores, os direitos sociais das crianças e dos velhos, das mulheres, dos consumidores, do meio ambiente, etc". Acesso à Justiça, In: Revista do Ministério Público, n. 18, p. 9.

6 François Ost cita algumas características que afastam para sempre a projeção contraditória entre direito subjetivo e interesse: "A) O interesse, estando na base dos principais conceitos jurídicos, mesmo na de direito subjetivo, tem assim, um caráter onipresente, aparecendo, desta forma, para além das pretensões asseguradas pela ordem jurídica; B) Paralelamente a esta onipresença e, talvez em conseqüência mesmo desta presença constante, a 
coletividade; referem-se a categorias inteiras de indivíduos e exigem uma intervenção ativa, não somente uma negação, um impedimento de violação - exigem uma atividade. Contrariamente a um direito excludente, negativo e repressivo, com feição liberal, tem-se um direito comunitário, positivo, promocional, de cunho transformador ${ }^{7}$.

O ponto central da questão deixa de ser o individual, passando a ser predominantemente o coletivo ('lato sensu'). A socialização e a comunitarização dos interesses têm papel fundamental'

Assim, observa-se que os interesses transindividuais (coletivos, em sentido estrito + difusos) escapam da dimensão privada do modelo jurídico liberal e se caracterizam por uma amplitude não apenas jurídica, em sentido estrito, mas também socioeconômica, tendo em vista que importam muitas vezes no desapego, afastamento e/ou negação dos postulados liberais tradicionalmente aceitos como meios de sanabilidade das controvérsias. Portanto a variabilidade e a complexidade dessas questões coletivas fazem com que caminhos distintos para sua resolução devam ser adotados. A resolução dos conflitos coletivos reclama a negação dos postulados do modelo liberal/ individualista.

\section{A TUTELA JURISDICIONAL DOS INTERESSES TRANSINDIVIDUAIS NO DIREITO BRASILEIRO POR MEIO DA LEI DA AÇÃO CIVIL PÚBLICA}

A ação civil pública disciplina a responsabilidade por danos causados ao meio ambiente, a bens e direitos de valor artístico, estético, histórico, turístico, paisagístico e qualquer outro interesse difuso ou coletivo. ${ }^{9}$

Sofreu profundas alterações com a edição do Código de Defesa do Consumidor (Lei 8.078, de 11 de setembro de 1990), por meio do disposto no artigo 117, que the acrescentou o artigo 21 , que dispõe aplicar-se "... à defesa dos direitos e interesses difusos, coletivos e individuais, no que for cabível, os Dispositivos do Título III da Lei que instituiu o Código de Defesa do Consumidor."

noção de interesse se caracteriza por uma imprecisão no seu significado, o que implica uma recorrente confusão e, mesmo, identificação entre interesse e direito; C) De outro lado, o interesse adquire, como noção funcional ou operatória, uma leveza (souplesse) que contrasta com a rigidez própria do direito subjetivo. Assim é que, à titularidade exclusivista do direito subjetivo se contrapõe a titularidade difusa, indeterminada ou coletiva dos interesses; da mesma forma, os interesses estão vinculados a valores novos especificados, apontando para objetivos abertos, ampliados; D) Por fim, o interesse incorpora um traço subversivo, apontando novos atores, novos objetos, bem como implica uma relativização de direitos tradicionais - o caso da propriedade que vê agregada a noção de função social, assumindo um interesse difuso da coletividade - é exemplar. A preferência pela utilização do termo direito apenas para o âmbito dos interesses juridicamente protegidos que têm sua titularidade ligada ao indivíduo aponta para os vínculos que se estabelecem entre a noção de direito e sua projeção como direito individual, uma tradição vinculada ao liberalismo. Assim, direito seria aquele fato juridicamente definido para o qual temos uma titularidade e um sujeito definidos, além de um objeto perfeitamente delimitado, ou seja, identifica-se com a noção de direito subjetivo. Há, entre direito e interesse, uma vinculação na qual à preponderância daquele se reflete uma negação deste. Ou seja: a hegemonia do direito subjetivo implica a desqualificação do interesse como portador de alguma relevância jurídica". Ver: Entre Droit et Non-Droit: I 'intérêt - Essai sur les fonctions qu 'exerce la notion d'intérêt en droit privé, p. 106-107.

7 Cf. José Luís Bolzan Morais, Do direito social aos interesses transindividuais: o Estado e o Direito na ordem ontemporânea, p. 96.

8 Lênio Streck, afirma que "o Estado Democrático de Direito representa, assim, a vontade constitucional de realização do Estado Social. É nesse sentido que ele é um plus normativo em relação ao direito promovedor-intervencionista próprio do Estado Social de Direito. Registre-se que os direitos coletivos, transindividuais, por exemplo, surgem no plano normativo, como conseqüência ou fazendo parte da própria crise do Estado Providência". Hermenêutica jurídica e (m) crise, p. 37.

9 A expressão "qualquer outro interesse difuso ou coletivo" vem prevista no inciso IV do artigo $1 .^{\circ}$ da lei 7.347 e foi acrescentado pelo artigo 110 do Código de Defesa do Consumidor.

A lei da ação civil pública visa também à tutela dos interesses individuais homogêneos, conforme refere Ada Pellegrini Grinover, no Parecer publicado na Revista de Direito do Consumidor, n. 5, p. 212 (A LACP destina-se hoje à tutela processual dos interesses difusos, coletivos e individuais homogêneos). Fundamenta tal entendimento a partir do artigo 117 do Código de Defesa do Consumidor. 


\section{INTERESSES TUTELADOS PELA AÇÃO CIVIL PÚBLICA}

Nos termos do artigo 1.0 da Lei 7.347, de 24-7-85 (Lei da Ação Civil Pública), "regem-se pelas disposições desta lei, sem prejuízo da ação popular, as ações de responsabilidade por danos morais e patrimoniais causados: I - ao meio ambiente; II - ao consumidor; III - a bens e direitos de valor artístico, estético, histórico, turístico e paisagístico; IV - a qualquer outro interesse difuso ou coletivo; por infração da ordem econômica".

O dispositivo supra transcrito contém um elenco meramente exemplificativo, na exata medida em que admite a tutela de "qualquer outro interesse difuso ou coletivo". ${ }^{10}$ Tanto os interesses coletivos 'stricto sensu' quanto os interesses difusos fazem parte de uma categoria maior que são os interesses coletivos 'lato sensu'. É possível falar-se dessa espécie de interesses sempre que uma situação favorável à satisfação de certo tipo de interesse possa determinar-se, não apenas em relação a um indivíduo isolado, mas frente a uma parcela ou todos os indivíduos que convivem em sociedade ou, ainda, que pertencem a determinado grupo.

Trata-se de interesses que se referem simultaneamente a mais de um indivíduo, ou seja, cada pessoa possui um interesse idêntico qualitativamente a outra e, portanto, não diferenciado. Conforme refere Mauro Cappelletti ${ }^{11}$, cada indivíduo que compõe a coletividade ou o grupo possui um interesse fragmentado, exatamente idêntico ao do outro que compõe essa mesma coletividade ou esse mesmo grupo.

Portanto os interesses coletivos não representam mera soma de interesses individuais da coletividade ou do determinado grupo social12, mas síntese ${ }^{13}$ dos mesmos, ou seja, o próprio interesse da coletividade ${ }^{14}$.

Tanto os interesses difusos quanto os interesses coletivos 'stricto sensu' se caracterizam pela indivisibilidade do objeto. Sendo indivisível, nenhum dos membros da sociedade ou do grupo será titular de direito subjetivo sobre o mesmo; o direito ao bem da vida indivisível é da própria coletividade ou do próprio grupo. Pertence a todos e ao mesmo tempo a ninguém em particular.

Conforme refere José Carlos Barbosa Moreira ${ }^{15}$, os interesses difusos se põem numa espécie de comunhão tipificada pelo fato de que a satisfação de um só implica, por força, a satisfação de todos,

10 A definição de tais tipos de interesses está prevista no art. 81 do Código de Defesa do Consumidor: "Art. 81. A defesa dos interesses e direitos dos consumidores e das vítimas poderá ser exercida em juízo individualmente ou a título coletivo. Parágrafo único: A defesa coletiva será exercida quando se tratar de: I - interesses ou direitos difusos, assim entendidos, para efeitos deste Código, os transindividuais, de natureza indivisível, de que sejam titulares pessoas indeterminadas e ligadas por circunstâncias de fato; II - interesses ou direitos coletivos, assim entendidos, para efeitos deste Código, os transindividuais de natureza indivisível de que seja titular grupo, categoria ou classe de pessoas ligadas entre si ou com a parte contrária por uma relação jurídica base;III - interesses ou direitos individuais homogêneos, assim entendidos os decorrentes de origem comum".

11 Tutela dos Interesses Difusos. In: Revista AJURIS, n. 33, p. 169.

12 Lúcia Valle Figueiredo entende dessa forma: "A somatória de interesses semelhantes leva ao agrupamento para sua melhor defesa. De seu turno, após o agrupamento, pode-se dar que o interesse coletivo não mais corresponda, pelo menos em parte, ao interesse individual". Direitos difusos e coletivos, p. 12.

13 Santoro Passarelli refere "che I 'interesse collettivo è l'interesse di una pluralità di persone a un bene idoneo a soddisfare un bisogno comune. Esso non è la somma di interessi individuali, ma la loro combinazione, ed è indivisibile nel senso che viene soddisfatto non già da più bene soddisfare il bisogno della collettività" apud VIGORITI, Vincenzo. Interessi collettivi e processo - la legittimazione ad agire, p. 47.

14 Rodolfo de Camargo Mancuso, ao tratar dos interesses coletivos em sentido estrito, segue o mesmo entendimento, ao afirmar: "Aqui o quadro se altera nitidamente. Não se trata da defesa do interesse pessoal do grupo; não se trata, tampouco, de mera soma ou justaposição de interesses individuais, atraídos por semelhança, harmonizados pelo fim comum, se amalgamam no grupo. É síntese antes que mera soma". Interesses difusos - conceito e legitimação para agir, p. 48. No mesmo sentido, Eduardo Grasso, ao referir que "I' interesse collettivo è stato generalmente individuato in un interesse (colto ancora nel significato socio-economico del termine, quale rapporto fra bisogno e bene idoneo ad appagarlo) riferibile simultaneamente a più individui: nel senso che ciascuno di essi ha o ritiene di avere un interesse identico (qualitativamente) a quello dell 'altro e quindi 'non differenziato' nel senso tradizionale. Codesta identità degli interessi individuali consentirebbe poi di considerare I 'insieme dei medesimi come 'appartenente' (anche) alla pluralità (o collettività), interessa quale entità a sé stante, non come mera somma dei singoli". In: Rivista di Diritto Processuale Civile, n. 1, 1983, p. 25.

15 In: Revista AJURIS, n. 32, p. 82, artigo intitulado 'A legitimação para a defesa dos interesses difusos no Direito Brasileiro'. 
assim como a lesão de um só constitui, ipso facto, lesão da inteira coletividade. Ou seja, todos os titulares, seja de interesse difuso ou coletivo, strictu sensu, serão beneficiados ou atingidos por decisão que dispuser sobre o bem ${ }^{16}$.

\section{CARACTERÍSTICAS ESPECÍFICAS DOS INTERESSES DIFUSOS}

A primeira delas diz respeito à indeterminação dos sujeitos; ou seja, há uma descoincidência com o interesse individual da pessoa, sendo impossível a identificação dos titulares do direito.

Essa indeterminação dos sujeitos se dá, em boa parte, em razão de inexistir um vínculo jurídico que agregue os sujeitos afetados pelo interesse difuso. As pessoas se unem apenas faticamente, ocasionalmente, em razão de certas circunstâncias e contingências, como, por exemplo, os habitantes de determinada localidade que consomem determinado produto ou os membros dessa mesma localidade que são atingidos pelos efeitos da poluição causada por determinada indústria química.

Outra característica marcante dos interesses difusos é a intensa conflituosidade interna que se revela na circunstância de que os interesses coletivos estão fluidos, soltos, disseminados entre segmentos sociais ou grupos. Tais conflitos não guardam as características dos conflitos individuais Caio versus Tício. Pelo contrário, há o entrechoque de massas de interesses, contrapondo constantes investidas de grupos versus grupos, em conflitos que se situam em ambos os polos. Por exemplo, a instalação de uma usina nuclear vai atrair posições favoráveis à sua implantação, assim como desfavoráveis (o governo é favorável, por ter outra fonte de energia, que poderá reduzir custos e empregar mais mão de obra; já os ecologistas dirão que a natureza ficará prejudicada com a instalação de tal tipo de indústria), como a construção de um aeroporto (de um lado, os comerciantes vizinhos vão desejar a existência do aeroporto nas proximidades, porque certamente aumentará o número de pessoas que transitarão na localidade, refletindo assim no volume de vendas; de outro, os moradores próximos certamente se manifestarão contra, em razão do alto índice de ruído gerado pelos supersônicos).

A maioria dos doutrinadores aponta a indivisibilidade do objeto, indeterminação dos sujeitos e a elevada litigiosidade/conflituosidade interna como característica dos interesses difusos. Todavia Rodolfo de Camargo Mancuso ${ }^{17}$ refere ainda uma quarta característica, que é a transitoriedade ou a mutação no tempo ou no espaço dos interesses difusos. Ou seja, em razão dos titulares dos interesses difusos não estarem ligados por uma relação jurídica-base, mas por circunstâncias de fato contingenciais, resulta que os mesmos são mutáveis na mesma proporção que essas situações fáticas. Os mesmos poderão aparecer ou desaparecer a qualquer momento, pois estão na dependência direta dessas situações.

\section{CARACTERÍSTICAS ESPECÍFICAS DOS INTERESSES COLETIVOS 'STRICTO SENSU'}

Os interesses coletivos, em sentido estrito, têm como característica fundamental, que os diferencia dos interesses difusos, "a determinabilidade das pessoas titulares, seja através de uma relação jurídica básica que as une (membros de uma associação de classe ou acionistas de uma mesma sociedade), seja por meio de um vínculo jurídico que as liga à parte contrária (contribuintes de um mesmo tributo, prestamistas de um mesmo sistema habitacional ou contratantes de um mesmo segurador com um mesmo tipo de seguro, estudantes de uma mesma escola, etc.)"18.

Por outro lado, tal espécie de interesse também é dotada de certa litigiosidade interna. Todavia, em menor grau do que nos interesses difusos, eis que os interesses coletivos estão agregados junto a grupos definidos, tendo em vista que, nos interesses coletivos, a representação é do tipo "convencional ou institucional, de sorte que a área conflituosa torna-se mais circunscrita: somente

16 No direito brasileiro, a Lei 8.078, de 11-9-90 (Código de Defesa do Consumidor), em seu artigo 81, incisos I e II, expressamente refere à natureza indivisível tanto dos interesses difusos quanto dos interesses coletivos.

17 Interesses difusos - conceito e legitimação para agir, p. 89.

18 Kazuo Watanabe et alii. Código brasileiro de defesa do consumidor comentado pelos autores do anteprojeto, p. 510. Em relação aos exemplos citados por esse autor, concordamos com o professor Sérgio Gilberto Porto, que coloca tais exemplos como hipóteses de interesses individuais homogêneos e não coletivos. Em todos esses exemplos, a indivisibilidade do objeto não está presente, restando afastada a caracterização como interesses coletivos. Revista AJURIS, n. 57, p. 138, nota n. ${ }^{\circ} 4$. 
um grupo determinado (família, sindicato, comuna) é portador legitimado desses interesses. Ao passo que, nos interesses difusos, a determinação dos sujeitos e a mobilidade e fluidez do objeto ampliam ao infinito a área conflituosa"19.

\section{CARACTERÍSTICAS DOS INTERESSES INDIVIDUAIS HOMOGÊNEOS}

Os interesses individuais heterogêneos têm como característica fundamental a circunstância de que determinada situação favorável em uma demanda possa se dar apenas em relação a um indivíduo isoladamente, diverso do que ocorre nos interesses coletivos, conforme já mencionado.

Já os interesses individuais homogêneos ${ }^{20}$ não são coletivos em sua essência ou no modo como são exercidos. Todavia apresentam uniformidade, "... pela circunstância ou no modo como são exercidos..." e "... pela circunstância de que seus titulares se encontram em certas situações ou enquadrados em certos segmentos sociais, que lhes confere coesão ou aglutinação, suficientes para destacá-los da massa de indivíduos isoladamente considerados".

Tal espécie de interesse se caracteriza pela divisibilidade do objeto e pela origem comum. Como exemplos, pode-se citar um grupo de alunos de uma determinada escola que se beneficiariam com determinado desconto, os contribuintes de determinado tributo inconstitucional, etc.

Feitas estas breves considerações a respeito dos interesses tutelados pela ação civil pública necessárias ao desenvolvimento deste trabalho - passar-se-á ao exame dos limites subjetivos da coisa julgada da sentença proferida nesta espécie de demanda e de sua respectiva problemática. Tal tema é bastante palpitante, tendo levantado profundas críticas.

\section{LIMITES SUBJETIVOS DA COISA JULGADA NA AÇÃO CIVIL PÚBLICA}

Herdamos da tradição romana, segundo Cândido Rangel Dinamarco ${ }^{21}$, a denominada singularidade da tutela jurisdicional, que está assentada no sólido tripé: (a) legitimidade necessariamente individual; (b) efeitos da sentença, limitados exclusivamente às partes; (c) limitação subjetiva rigorosa da autoridade da coisa julgada.

A tríade acima declinada criou e sedimentou a tradição de um processo marcado pelo individualismo, característico do sistema processual europeu-continental, ao qual se filiou o Brasil. Todavia a modificação desse tripé se impunha como forma de possibilitar a defesa em juízo dos interesses metaindividuais ${ }^{22}$.

Portanto o processo necessariamente precisou romper, de certa forma, com o individualismo, de modo a possibilitar a defesa em juízo dos interesses metaindividuais.

No âmbito do direito processual civil está a coisa julgada. No tocante a ela - mais precisamente em relação a seus limites subjetivos -, o processo civil tradicional também não resolvia a problemática dos interesses metaindividuais. A Lei da Ação Civil Pública, no artigo 16, tratou do tema pioneiramente. Posteriormente, o artigo 103 do Código de Defesa do Consumidor ${ }^{23}$ também contemplou essa respectiva matéria.

19 Rodolfo de Camargo Mancuso, Interesses difusos - conceito e legitimação para agir, p. 85.

20 Estão previstos no inciso III do artigo 81 do Código de Defesa do Consumidor brasileiro, já transcrito.

21 A reforma do Código de Processo Civil, p. 28.

22 Neste sentido, vide José Marcelo Menezes Vigliar, Ação civil pública, p. 105.

23 O artigo 103 não se refere apenas às ações tratadas pelo Código de Defesa do Consumidor, muito embora refira no 'caput' "as ações de que trata este Código". Possui uma abrangência maior, à luz do que dispõe o artigo 117 do mesmo diploma legal, que acrescentou o artigo 21 à Lei da Ação Civil Pública, determinando a aplicação "à defesa dos direitos e interesses difusos, coletivos e individuais, no que for cabível, os dispositivos do Título III da Lei que instituiu o Código de Defesa do Consumidor". Também o artigo 110 do Código de Defesa do Consumidor acrescentou o inciso IV ao art. $1 .^{\circ}$ da Lei 7.347/85, estendendo a abrangência a "qualquer outro interesse difuso ou coletivo". Por outro lado, a Lei da Ação Civil Pública é aplicável às ações previstas pelo Código de Proteção e Defesa do Consumidor, 'verbis': "Art. 90. Aplicam-se às ações previstas neste título as normas do Código de Processo Civil e da Lei n. ${ }^{0}$ 7.347, de 24 de julho de 1985, inclusive no que respeita ao inquérito civil, naquilo que não contrariar suas disposições". 


\section{A COISA JULGADA NAS AÇÕES EM DEFESA DE INTERESSES DIFUSOS}

A disciplina jurídica da coisa julgada nas ações coletivas em defesa de interesses difusos é prevista pelo artigo 103, inciso I, combinado com o seu $\S 1^{\circ}$, acima mencionados.

A regra geral para a espécie, adotada pelo Código de Defesa do Consumidor, é a da coisa julgada erga omnes, limitada à competência territorial do órgão prolator nos termos do artigo 16 da Lei da Ação Civil Pública.

Ainda como regra geral, o inciso I do artigo 103 incorporou as soluções já adotadas pelas leis da Ação Popular ${ }^{24}$ e da Ação Civil Pública - coisa julgada 'secundum eventum litis' - nos casos de improcedência da demanda coletiva por insuficiência de provas, em que qualquer legitimado poderá intentar novamente a ação, valendo-se de nova prova.

A partir do artigo 103, inciso I, do Código de Defesa do Consumidor, cabe distinguir três hipóteses. A primeira delas refere-se ao caso de acolhimento do pedido formulado na ação coletiva. A sentença prevalecerá em relação a todos os membros da coletividade, que poderão beneficiarse da coisa julgada no sentido de satisfazer suas pretensões individuais. A segunda diz respeito à hipótese de quando é rejeitado o pedido, tendo sido julgado o mérito da ação. Neste caso, os efeitos se produzirão erga omnes em relação a todos os legitimados do artigo 82 , o que impedirá o ajuizamento de nova ação coletiva com o mesmo fundamento. A terceira hipótese se dá quando o pedido é rejeitado por insuficiência de provas. A sentença não se revestirá de autoridade de coisa julgada material. Qualquer legitimado (inclusive o que propôs a primeira demanda) poderá intentar novamente a ação, com idêntico fundamento.

\section{A COISA JULGADA NAS AÇÕES EM DEFESA DE INTERESSES COLETIVOS}

É disciplinada pelo inciso II do artigo 103 do Código de Defesa do Consumidor, cominado com o seu $\S 1 .^{\circ}$. O regime estabelecido para a coisa julgada nas ações em defesa de interesses coletivos é exatamente o mesmo estabelecido para as ações em defesa de interesses difusos.

A diferença existente entre os mesmos reside na extensão da coisa julgada em relação aos terceiros. Nas ações em defesa de interesses difusos, a extensão da coisa julgada se dá sobre toda a coletividade. Já nas ações em defesa de interesses coletivos, a natureza dos interesses coletivos restringe a coisa julgada aos membros da categoria ou classe, ligados entre si ou com a parte contrária por uma relação jurídica base, respeitada a competência territorial do magistrado prolator da decisão.

\section{A COISA JULGADA NAS AÇÕES EM DEFESA DE INTERESSES INDIVIDUAIS HOMOGÊNEOS}

O artigo 103, inciso III, do Código de Defesa do Consumidor, combinado com seu $\S 2 .^{\circ}$, disciplinam a matéria.

24 Rodolfo de Camargo Mancuso refere: "No Direito brasileiro tal sistema foi acolhido no art. 18 da lei sobre a ação popular constitucional (n. $4.717 / 65)$, dispondo que a coisa julgada será 'oponível erga omnes, exceto no caso de haver sido a ação julgada improcedente por deficiência de prova'. Quer dizer, o efeito preclusivo geral fica dependendo do resultado final, e, mais que isso, será preciso verificar, em caso de improcedência, qual foi a causa da rejeição. Para José Afonso da Silva tal dispositivo é inconstitucional, porque um processo, como tal, 'só existirá quando conduza a uma decisão de mérito em definitivo, com autoridade de coisa julgada material, salvo nos casos expressos da cláusula rebus sic stantibus'. E, citando E. Couture: 'o que caracteriza a idéia de processo é o seu fim: 'a decisão do conflito mediante uma sentença que adquire autoridade de coisa julgada'. Sem isso, a decisão emitida não passará de um simulacro de julgamento ...' . Há, todavia, vozes favoráveis a esse sistema. J. C. Barbosa Moreira acha 'interessante' a solução alvitrada por esse art. 18, julgando-a, 'de lege ferenda', merecedora de extensão a hipóteses análogas. A. P. Grinover perfilha opinião análoga. (...) Efetivamente, mais uma aplicação essa fórmula secundum eventum litis vem de ocorrer no Direito brasileiro: a Lei federal 7.347 (DOU 25-7-85), que dispõe sobre a ação civil pública em caso de danos ao meio ambiente, ao consumidor e a bens e direitos de valor artístico, estético, histórico, turístico e paisagístico, previu em seu artigo 16, que a sentença 'fará coisa julgada erga omnes', exceto se a ação for julgada improcedente por deficiência de provas, hipótese em que qualquer legitimado poderá intentar outra ação com idêntico fundamento, valendo-se de nova prova." In: Revista dos Tribunais, n. 608, p. 30. 
O tratamento dado aos limites subjetivos da coisa julgada é semelhante ao das ações em defesa de interesses difusos e coletivos. Todavia há duas diferenças significativas. A primeira é a inexistência de coisa julgada erga omnes na hipótese de improcedência do pedido - por qualquer razão - na ação coletiva que tutele interesses individuais homogêneos; neste caso, apenas as pessoas que integraram a lide serão atingidas pela coisa julgada. Ou seja, a coisa julgada atua erga omnes com o temperamento de só beneficiar todas as vítimas e os sucessores, sem prejudicar os terceiros que não tenham intervindo no processo. A segunda das diferenças se dá tendo em vista que, no caso de improcedência da ação coletiva por insuficiência de provas, as pessoas que eventualmente tenham intervindo no processo serão atingidas pela coisa julgada (o que não ocorre nos casos de improcedência, por insuficiência de prova, das ações coletivas que tutelem interesses difusos ou coletivos). Ou seja, o Código de Defesa do Consumidor, nesta hipótese, também adotou a extensão subjetiva do julgado 'secundum eventum litis', na exata medida em que apenas a decisão favorável atingirá o grupo.

\section{LIMITAÇÃO IMPOSTA PELA NOVA REDAÇÃO DO ARTIGO 16 DA LEI DA AÇÃO CIVIL PÚBLICA AOS LIMITES SUBJETIVOS DA COISA JULGADA}

O artigo 16 da Lei da Ação Civil Pública - alterado pela Lei 9.494/97, que teve origem na MP 1.570/97 - vinculou coisa julgada à competência territorial do órgão prolator da decisão.

A vinculação dos limites subjetivos da coisa julgada na ação civil pública à competência territorial do magistrado prolator da decisão tem suscitado inúmeras críticas. Primeiro, por ter restringido ao extremo os limites subjetivos da coisa julgada ao atrelá-los à competência territorial dos magistrados que julgam as demandas de natureza coletiva. Trata-se de um tratamento incompatível com o escopo da lei da ação civil pública, que sempre foi o de uma tutela coletiva ampla. Segundo, porque a alteração - ainda que equivocada - deveria ter sido operada no Código de Defesa do Consumidor: o Executivo teria demonstrado que conhecia a sistemática de reciprocidade criada pelas Leis 7.347/85 e 8.078/90 e, assim, optado pela reforma do sistema da coisa julgada num diploma mais atual, mais completo. Terceiro, porque em sendo os interesses coletivos essencialmente indivisíveis, não há como limitar os efeitos da coisa julgada a determinado território, havendo o seríssimo risco de decisões contraditórias.

Não é demasiado referir que essa mesma questão pode ser observada de outro ângulo. Nos limites de competência territorial e funcional estabelecidos na Lei n. 0 7.347/85, o foro ordinário para a ação civil pública será definido pelo local onde ocorreu o dano. Não raras vezes, os efeitos de um ato ilícito repercutem e se estendem de forma inexorável para muito além das fronteiras definidas pela geografia humana. É impossível de evitar-se a propagação do dano por decreto ou medida cautelar ou muitas vezes de determinar-se sua real abrangência; não se pode legitimamente limitar os efeitos da coisa julgada. Por exemplo: do derramamento de petróleo no Porto de Rio Grande, resultam danos incalculáveis ao meio ambiente regional, pois as marés rapidamente espalham a mancha de óleo por quase todo o litoral gaúcho; em outra, ao município vizinho de Pelotas, e assim por diante. Neste e em casos análogos, a apuração da responsabilidade via condenação in pecunia, determinação da cessação da atividade nociva ou de recomposição do bem jurídico tutelado, quando pertinentes, necessariamente extrapolará, em seus efeitos, os limites da competência territorial do órgão prolator da sentença, determinada de forma absoluta pelo local onde ocorreu o dano, no exemplo, a Comarca de Rio Grande.

A partir desse exemplo, deduz-se facilmente a incompatibilidade da restrição territorial aos efeitos da coisa julgada, quando se fala em tutela de interesses indivisíveis por natureza.

Uma nova visão dos limites subjetivos da coisa julgada na ação civil pública só será alcançada por meio de uma análise hermenêutica da problemática e não apenas do ponto de vista meramente dogmático. 


\title{
A NECESSIDADE DE (RE)DIMENSIONAR OS LIMITES SUBJETIVOS DA COISA JULGADA NA AÇÃO CIVIL PÚBLICA DE MODO A ASSEGURAR A EFETIVAÇÃO DE DIREITOS FUNDAMENTAIS
}

\author{
HERMENÊUTICA JURÍDICA E LINGUAGEM: UM RUMO À INTERPRETAÇÃO PRODUTIVA
}

A interpretação geralmente trabalha com conceitos prévios, cuja tendência é a de serem substituídos progressivamente por outros mais adequados. Aquele que intenta compreender está exposto aos erros de opiniões prévias que não se comprovam nas coisas mesmas. A compreensão só alcança as suas verdadeiras possibilidades quando as opiniões prévias com as que inicia não são arbitrárias. Em razão desta circunstância, é importante que o intérprete não se dirija aos textos diretamente, desde as opiniões prévias que Ihes subjazem, senão que examine tais opiniões em relação à sua legitimação, isto é, como sua origem e validade.

Para Hans Georg Gadamer25, o que se exige é simplesmente estar aberto à opinião do outro ou à do texto. Mas esta abertura implica que se coloque a opinião do outro em uma classe de relação com o conjunto das opiniões próprias ou que um se coloque em certa relação com as do outro ${ }^{26}$.

Isso significa dizer que aquele que pretende compreender não pode se entregar, desde o princípio, à sorte de suas próprias opiniões prévias e ignorar a mais obstinada e, consequentemente, possível opinião do texto. Aquele que pretende compreender um texto tem que estar, em princípio, disposto a deixar dizer algo por ele. Uma consciência formada hermeneuticamente tem que se mostrar receptiva, desde o princípio, para a condição do texto.

Todavia esta receptividade não pressupõe nem neutralidade frente às coisas, senão que inclui uma matizada incorporação das próprias opiniões prévias e (pré)juízos. O que importa é fazer-se a mediação das próprias antecipações, com o fim de que o texto mesmo possa se apresentar em sua condição e obtenha assim a possibilidade de confrontar a sua verdade objetiva com as próprias opiniões prévias.

\section{A COMPREENSÃO COMO COMPORTAMENTO PRODUTIVO}

A partir da experiência linguística nasce a dimensão universal do fenômeno da compreensão, da hermenêutica. Compreender ${ }^{27}$ não significa simples reprodução daquilo que o outro fala ou pensa. O compreender significa, primariamente, entender-se na coisa e só secundariamente destacar e

25 "Lo que se exige es simplesmente estar abierto a la opinión del otro o a la del texto. Pero esta apertura implica siempre que se puede la opinión del otro en alguna clase de relación con el conjunto de las opiniones propias, o que uno se pone en cierta relación con las de otro. Claro que las opiniones son posibilidades variadas y cambiantes (en comparación con la univocidad de un lenguaje o de un vocabulario), pero dentro de esta multiplicidad de lo opinable, esto es, de aquello a lo que un lector puede encontrar sentido y que en consecuencia puede esperar, no todo es posible, y el que pasa de largo por lo que el otro está diciendo realmente tampoco podrá en último extremo integrar por entero lo que entendió mal en sus propias y variadas expectativas de sentido". Verdad y metodo I, p. 335.

26 No mesmo sentido R. Dworkin, El imperio de la justicia, p. 56 ("De modo que cada uno de los participantes de una prática social debe distinguir estre tratar de distinguir lo que otros miembros de su comunidad piensan que necesita la práctica y tratar de decidir, por sí mismo, qué es lo que dicha práctica necesita en realidad").

27 Cf. Hans Georg Gadamer, "esto implica traer a primer plano lo que en hermenéutica anterior siempre quedaba al margen: la distancia en el tiempo y su significación para la comprensión. Importa destacar esto sobre todo frente a la teoria hermenéutica del romanticismo. Recordaremos que ésta pensaba la comprensión como la reproducción de una producción originaria. Por eso podía colocarse bajo la divisa de que hay que llegar a comprender a um autor mejor de lo que él mismo se comprendía. (...) Por eso la comprensión no es nunca un comportamiento sólo reproductivo, sino que es a su vez siempre productivo. ... Comprender no es comprender mejor, ni en el sentido objetivo de saber más en virtud de conceptos más claros, ni en el de la superioridad básica que posee lo consciente respecto a lo inconsciente de la producción. Bastaría decir que, cuando se comprende, se comprende de un modo diferente. Este concepto de la comprensión rompe desde luego el círculo trazado por la hermenéutica romántica". Verdad y metodo I, p. 365. 
compreender a opinião do outro como tal. Por isso, a primeira de todas as condições hermenêuticas é a (pré)compreensão, que surge do ter que ver com o mesmo assunto.

A hermenêutica tem que partir da premissa de quem quer compreender deve estar vinculado ao assunto que se expressa na tradição. Desta posição, segue que a tarefa da hermenêutica não é desenvolver um procedimento da compreensão, mas, sim, iluminar as condições abaixo das quais se compreende. Mas estas condições não são todas do tipo de procedimentos ou métodos, nem o que compreende poderia colocá-las por si mesmo na aplicação; estas condições têm que estar dadas. Os (pré)juízos e opiniões prévias que ocupam a consciência do intérprete não estão à sua disposição; este não está em condições de distinguir por si mesmo os (pré)juízos produtivos que fazem possível a compreensão daqueles outros que a obstacularizam e produzem os mal-entendidos.

Esta distinção só pode ter lugar na compreensão mesma e, por isso, é coisa que a hermenêutica pergunta como se realiza. Todavia isto implica trazer, em primeiro plano, o que, na hermenêutica anterior, sempre ficava à margem: a distância no tempo e a sua significação para a compreensão. ${ }^{28}$

Cada época entende um texto transmitido de uma maneira peculiar, pois o texto forma parte de um conjunto de uma tradição pela qual cada época tem um interesse objetivo e na que intenta compreender-se a si mesma. O verdadeiro sentido de um texto, tal como este se apresenta a seu intérprete, não depende do aspecto puramente ocasional que representam o autor e o seu público originário; ou pelo menos não se esgota nisso, tendo em vista que este sentido está sempre determinado também pela situação histórica do intérprete e, em consequência, pelo todo do processo histórico.

O sentido de um texto supera ao seu autor não ocasionalmente, mas sim, sempre. Por isso a compreensão nunca é um comportamento apenas reprodutivo, senão que é sempre produtivo ${ }^{29}$. Compreender não é compreender melhor, nem no sentido objetivo de saber mais em virtude de conceitos mais claros, nem na de superioridade básica que possui o consciente respeito ao inconsciente

28 Hans Georg Gadamer destaca esta questão frente à teoria hermenêutica do romanticismo. A mesma pensava a compreensão como a reprodução de uma produção originária. Por isso podia colocar-se abaixo a divisa de que se pode chegar a compreender um autor melhor do que o mesmo se compreendia. $O$ entendimento que a compreensão ulterior possa ter uma superioridade de princípios frente à produção originária e possa formular-se como um compreender melhor não repousa na realidade sobre um fazer consciente posterior, capaz de equiparar o intérprete com o autor original, senão que pelo contrário remete a uma diferença insuperável entre o intérprete e o autor, diferença que está dada pela distância histórica. Verdad y metodo I, p. 225-276.

29 Para R. Dworkin, "interpretar una práctica social es sólo una forma u ocasión de interpretación. Las personas interpretan en muchos contextos diferentes, y deberíamos comenzar tratando de hallar algún sentido sobre la manera en que estos contextos difieren. La ocasión más familiar de interpretación, tan familiar que casi no la reconocemos como tal, es la conversación. Interpretamos los sonidos o marcas que hace otra persona para decidir lo que está dicho. La llamada interpretación científica tiene otro contexto: decimos que un científico primero recoge datos y luego los interpreta. La interpretación artística tiene tambiém otro: los críticos interpretan poemas, obras de teatro, pinturas para defender algún propósito de su significado, tema o sentido. La forma de interpretación que estudiamos, la interpretación de la práctica social, es como la interpretación artística en el siguiente sentido: ambas apuntan a interpretar algo creado por personas como una entidad distinta de ellas, en lugar de lo que las personas dicen, como en la interpretación de la conversación o los sucesos no creados por las personas, como en la interpretación científica. Sacaré provecho de dicha similitud entre la interpretación artística y la interpretación de la práctica social, denominaré ambas formas como forma de interpretación 'creativa'para distinguirlas de la interpretación científica y de la conversación. (...) Ofrezco esta descripción constructiva sólo como análisis de la interpretación creativa. Pero también debemos notar cómo la descripción constructiva puede ser elaborada en forma tal que se adapte a los otros dos conceptos interpretativos que mencioné anteriormente, y mostrar así una profunda conexión entre todas las formas de interpretación. (...) Por lo tanto, la descripción constructiva de la interpretación creativa podría tal vez proporcionar una descripción más general de todas las formas de interpretación. Diríamos entonces que cada interpretación lucha por hacer de un objeto lo mejor que puede ser, como un ejemplo de uma empresa supuesta, y esa interpretación adquiere formas diferentes en contextos diferentes sólo porque distintas empresas adoptan distintas normas de valor o de éxito. La interpretación artítica se diferencia de la interpretación científica sólo porque juzgamos el éxito de las obras de arte con normas diferentes de las que usamos para juzgar una explicación de los fenómenos físicos"). El imperio de la justicia, p. 47 e 49. 
da produção. Bastaria dizer que, quando se compreende, compreende-se de um modo diferente. Este conceito de compreensão rompe, desde logo, o círculo traçado pela hermenêutica romântica.

A compreensão incrementa sempre o significado de um texto e, assim, forma parte do processo histórico que atualiza o passado. Neste sentido, a hermenêutica é um pressuposto ontológico do mesmo compreender. É anterior ao uso dos métodos; trata-se de uma teoria acerca do cognoscente.

Outro fato a destacar é que, no mundo do Direito, também acontece a distância temporal entre norma e intérprete. Isto pode ser considerado como uma via que salva as dificuldades da tarefa interpretativa. É essa distância que facilitará o "significado" do Direito; por outro lado evidencia a "disparidade" de situações entre promulgação da norma e da interpretação de hoje. Portanto a distância temporal é a que confere ao intérprete a possibilidade positiva e produtiva do compreender.

A distância no tempo deriva da mesma natureza do Direito e não só de uma hipotética inadequação e situação duvidosa, não prevista em lei. Nessa exigência, reside a mesma generalidade da norma, que sempre necessita de uma concretização e aplicação que lhe facilite sua necessária hermenêutica, enquanto são normas diretivas de condutas concretas.

Assim, compreender aquilo que alguém diz significa harmonizar-se com a coisa referida e não se transferir para esse alguém, repetindo suas vivências. Tal processo dialógico com outrem se caracteriza sempre como um fato de linguagem, que é o meio através do qual os interlocutores se compreendem e no qual se verifica o entendimento da coisa sobre a qual se fala.

O Direito deve ser entendido como uma prática dos homens, expressa por meio do discurso, sendo mais que palavras, comportamentos, símbolos, conhecimentos. É o que a lei manda, mas também o que os juízes interpretam, os advogados argumentam, as partes declaram, os teóricos produzem, os legisladores sancionam ou os doutrinadores criticam. Enfim se trata de um discurso constitutivo, uma vez que designa/atribui significados a fatos e palavras.

Portanto a hermenêutica deve assumir o seu papel de (inter)mediação e, portanto, de produção/ atribuição/adjudicação do sentido.

Fazer hermenêutica jurídica é realizar um processo de compreensão do Direito; é desconfiar do mundo e das suas certezas.

\section{A NECESSIDADE DE UMA (RE)LEITURA DOS LIMITES SUBJETIVOS DA COISA JULGADA NA AÇÃO CIVIL PÚBLICA A PARTIR DA HERMENÊUTICA JURÍDICA}

O artigo 5. ${ }^{\circ}$, inciso XXXVI, da Constituição Federal dispõe que "a lei não prejudicará o direito adquirido, o ato jurídico perfeito e a coisa julgada". Ou seja, em nenhum momento o texto constitucional vincula coisa julgada à competência. Trata-se de institutos de direito processual absolutamente diversos. Tanto isto é verdade que as sentenças proferidas nas ações individuais têm sua eficácia inter partes oposta em qualquer lugar do país! Jamais houve qualquer vinculação entre coisa julgada e competência. Logo se pode afirmar a inconstitucionalidade do artigo 16 da LACP à luz do artigo 5. ${ }^{\circ}$, inciso XXXVI, da Magna Carta, que restringiu a coisa julgada aos limites territoriais, quando o texto constitucional não faz qualquer restrição. Ao tratar do tema, leciona Rodolfo de Camargo Mancuso ${ }^{30}$ :

\footnotetext{
Qualquer sentença proferida por órgão do Poder Judiciário pode ter eficácia para além de seu território. Até a sentença estrangeira pode produzir efeitos no Brasil, bastando para tanto que seja homologada pelo STF (agora STJ). Assim, as partes entre as quais foi dada a sentença estrangeira são atingidas por seus efeitos onde quer que estejam no planeta Terra. Confundir jurisdição e competência é, no mínimo, desconhecer a ciência do direito.

Com efeito, o problema atinente a saber quais pessoas ficam atingidas pela imutabilidade do comando judicial insere-se na rubrica dos limites subjetivos desse instituto processual dito 'coisa julgada', e não sob a óptica de categorias outras, como a jurisdição, a competência, a organização judiciária.
}

30 In: Ação civil pública: em defesa do meio ambiente, do patrimônio cultural e dos consumidores. 11. ed. São Paulo: Revista dos Tribunais, 2009, p. 322-323. 
Por outro lado, o artigo 16 da LACP, ao vincular os limites subjetivos da coisa julgada na ação civil pública à competência territorial do órgão prolator do decisum, não atentou para o princípio constitucional da isonomia ${ }^{31}$, previsto no artigo $5 .^{\circ}$, caput, da Magna Carta. Evidentemente que a restrição dos limites subjetivos da coisa julgada na ação civil pública conduz à proliferação tanto de ações individuais quanto coletivas. Consequentemente, há o sério risco de tratamento diferenciado para demandas que contemplam o mesmo objeto com a possibilidade de decisões contraditórias.

O princípio isonômico ${ }^{32}$ tem dupla significação: política, como repulsa a privilégios injustificados; e de efetividade, como igualizador, ajudando a aplicação da norma em caso de insuficiência ou inadequada igualdade diante das peculiaridades de um caso concreto.

Não é demasiado referir que a aplicação do artigo 16 da LACP poderá ainda deixar desprovida de tutela uma larga parcela da população brasileira, face à limitação territorial instituída -, o que poderá conduzir à não efetividade de direitos fundamentais e ao desrespeito a princípios constitucionais. Isto ocorre por uma simples e incontestável razão: é exatamente dentro dos princípios constitucionais que se encontram as normas relativas aos direitos fundamentais ${ }^{33}$, devendo ser afastada, por essa razão, a interpretação literal do referido dispositivo legal. Assim, a aplicação do artigo 16 da LACP poderá acarretar - o que ocorre na grande maioria dos casos - choque com algum princípio que estabeleça algum direito fundamental.

Evidentemente que, em se tratando de limites subjetivos da coisa julgada na ação civil pública, devem preponderar os princípios que garantam a aplicação e a efetivação dos direitos fundamentais. Assim, se a limitação territorial imposta pelo artigo 16 da LACP impedir a aplicação e a efetivação de direitos fundamentais - como efetivamente restringe na maioria dos casos -, deverá ser dado um conteúdo mais amplo ao mesmo.

Por derradeiro, o artigo 93 do Código de Defesa do Consumidor não deixa dúvida de que os limites subjetivos da coisa julgada na ação civil pública devam ir além da competência territorial do magistrado prolator da decisão, verbis:

Art. 93. Ressalvada a competência da justiça federal, é competente para a causa a justiça local:

I - no foro do lugar onde ocorreu ou deva ocorrer o dano, quando de âmbito local;

II - no foro da Capital do Estado ou no do Distrito Federal, para os danos de âmbito nacional ou regional, aplicando-se as regras do Código de Processo Civil aos casos de competência concorrente.

A partir do dispositivo legal transcrito, pode-se também concluir que, se a ação deve ser ajuizada no foro do local do dano, os limites subjetivos da coisa julgada da ação civil pública devem ir além da competência territorial do órgão prolator da decisão. Se fosse o contrário, a ação poderia ser ajuizada em qualquer foro (e não naquele onde ocorreu ou deva ocorrer o dano!). O mesmo raciocínio pode ser feito para os danos no âmbito nacional ou regional. Esse também é o entendimento de Ada Pellegrini Grinover ${ }^{34}$ :

31 Segundo Rui Portanova, "entende-se por princípio da igualdade a equiparação de todos que estejam submetidos a uma dada ordem jurídica no que se refere ao respeito, ao gozo e à fruição de direitos, assim como à sujeição a deveres." Princípios do Processo Civil, p. 35.

32 O jurista colombiano Devis Echandía, ao tratar da igualdade das partes ante a lei processual, leciona: "Dos consecuencias se deducen: 1) la de que en el curso del proceso las partes gozam de iguales oportunidades para su defensa, lo cual tiene fundamento en la máxima audiatur es altera pars, que viene a ser una aplicación del postulado que consagra la iagualdad de los ciudadanos ante la ley, base de la organización de los Estados modernos; 2) que no son aceptables los procedimientos privilegiados, al menos en relación com raza, fortuna o nacimiento de las partes. Pero debe procurarse que esa giualdad en el proceso sea real y no simplesmente teórica. Para ello se debe otorgar a los pobres y débiles oportunidad de verdadera defensa, (...)" Teoría General del Proceso, p. 56. Já Nelson Nery Jr., ao tratar do assunto leciona: "O art. 5.0, caput, e o inciso n. I da CF de 1988 estabelecem que todos são iguais perante a lei. Relativamente ao processo civil, verificamos que o princípio da igualdade significa que os litigantes devem receber do juiz tratamento idêntico. Assim, a norma do art. 125, n. I, do CPC teve recepção integral em face do novo texto constitucional. Dar tratamento isonômico às partes significa tratar igualmente os iguais e desigualmente os desiguais, na exata medida de suas desigualdades". Princípios do Processo Civil na Constituição Federal, p. 40.

33 Cf. W. S. GUERRA FILHO, Processo constitucional e direitos fundamentais, p. 44.

34 In: GRINOVER, Ada Pellegrini et alii. Código Brasileiro de Defesa do Consumidor: comentado pelos autores 
De início, os tribunais não perceberam o verdadeiro alcance da coisa julgada erga omnes, limitando os efeitos da sentença e das liminares segundo critério de competência. Logo, afirmamos não fazer sentido, por exemplo, que ações em defesa de interesses individuais homogêneos dos pensionistas e aposentados da Previdência Social ao recebimento da diferença de $147 \%$ fossem ajuizadas nas capitais dos diversos Estados, a pretexto dos limites territoriais dos diversos órgãos da justiça federal. O problema não é de competência: o juiz federal, competente para processar e julgar a causa, emite um provimento (cautelar ou definitivo) que tem eficácia erga omnes, abrangendo todos os aposentados e pensionistas do Brasil. Ou a demanda é coletiva, ou não o é; ou a coisa julgada é erga omnes, ou não o é. E se o pedido for efetivamente coletivo, haverá uma clara relação de litispendência entre as várias ações ajuizadas nos diversos Estados da Federação.

Por isso sustentamos que a limitação operada por certos julgados afronta o art. 103, CDC, e despreza orientação fornecida pelo art. 93, II, onde se vê que a causa que verse sobre reparação de danos no âmbito nacional ou regional deve ser proposta no foro da capital do Estado ou no Distrito Federal, servindo evidentemente, a decisão para todo o território nacional. Esse dispositivo aplica-se aos demais casos de interesses que alcancem grupos e categorias de indivíduos, mais ou menos determináveis, espalhados pelo território nacional.

Portanto, se o dano é de escala local, regional ou nacional, o juízo competente para proferir sentença, certamente, sob pena de ser inócuo o provimento, lançará mão de comando capaz de recompor ou indenizar os danos local, regional ou nacional, levados em consideração, para tanto, os beneficiários do comando, independentemente de limitação territorial.

\section{A JURISPRUDÊNCIA DO SUPERIOR TRIBUNAL DE JUSTIÇA E A AMPLIAÇÃO DOS LIMITES SUBJETIVOS DA COISA JULGADA NA AÇÃO CIVIL PÚBLICA}

A Corte Especial ${ }^{35}$ do Superior Tribunal de Justiça, recentemente, entendeu que a interpretação literal do art. 16 da LACP esvazia a utilidade prática da ação coletiva "porque, cuidando-se de dano de escala nacional ou regional, a ação somente pode ser proposta na capital dos Estados ou no Distrito Federal (art. 93, inciso II). Assim, a prosperar a tese do recorrente, o efeito erga omnes próprio da sentença estaria restrito às capitais, excluindo todos os demais potencialmente beneficiários da decisão".

Segundo o Rel. Luís Felipe Salomão, "o art. 16 da LACP baralha conceitos heterogêneos como coisa julgada e competência territorial - e induz a interpretação, para os mais apressados, no sentido de que os "efeitos" ou a "eficácia" da sentença podem ser limitados territorialmente, quando se sabe, a mais não poder, que a coisa julgada - a despeito da atécnica do art. 467 do CPC - não é um "efeito" ou "eficácia" da sentença, mas qualidade que a ela se agrega de modo a torná-la 'imutável e indiscutível".

Prossegue o relator do acórdão:

É certo também que a competência territorial limita o exercício da jurisdição e não os efeitos ou a eficácia da sentença, os quais, como é do conhecimento comum, correlacionam-se com os 'limites da lide e das questões decididas' (art. 468, CPC) e com as que o poderiam ter sido (art. 474, CPC) - tantum judicatum, quantum disputatum vel disputari debebat.

A apontada limitação territorial dos efeitos da sentença não ocorre nem no processo singular, e também, com mais razão, não pode ocorrer no processo coletivo, sob pena de desnaturação desse salutar mecanismo de solução plural das lides.

A prosperar tese contrária, um contrato declarado nulo pela justiça estadual de São Paulo, por exemplo, poderia ser considerado válido no Paraná; a sentença que determina a reintegração de posse de um imóvel que se estende a território de mais de uma unidade federativa (art. 107, CPC) não teria eficácia em relação a parte dele; ou uma sentença de divórcio proferida em Brasília poderia não valer para o judiciário mineiro, de modo que ali as partes pudessem ser consideradas ainda casadas, soluções todas elas teratológicas.

A questão principal, portanto, é de alcance objetivo ('o que' se decidiu) e subjetivo (em relação 'a quem' se decidiu), mas não de competência territorial.

do anteprojeto. 9. ed. Rio de Janeiro: Forense Universitária, 2007, p. 942.

35 Recurso Especial 1.243.887, Rel. Min, Luis Felipe Salomão, 19.10.2011. 
Pode-se afirmar, com propriedade, que determinada sentença atinge ou não esses ou aqueles sujeitos (alcance subjetivo), ou que atinge ou não essa ou aquela questão fático-jurídica (alcance objetivo), mas é errôneo cogitar-se de sentença cujos efeitos não são verificados, a depender do território analisado.

A antiga jurisprudência do STJ, segundo a qual a 'eficácia erga omnes circunscreve-se aos limites da jurisdição do tribunal competente para julgar o recurso ordinário' (REsp 293.407/SP, Quarta Turma, confirmado nos ERESp n. 293.407/SP, Corte Especial), em hora mais que ansiada pela sociedade e pela comunidade jurídica, deve ser revista para atender ao real e legítimo propósito das ações coletivas, que é viabilizar um comando judicial célere - em atenção à extensão do interesse metaindividual na lide.

Caso contrário, 'esse diferenciado regime processual não se justificaria, nem seria eficaz, e o citado interesse acabaria privado de tutela judicial em sua dimensão coletiva, reconvertido em multifárias demandas individuais' (MANCUSO, Rodolfo de Camargo, Op. Cit., p. 325) 'atomizando' as lides na contramão do moderno processo de 'molecularização' das demandas.

Com efeito, como se disse anteriormente, por força do art. 21 da Lei n. 7.347/05, o Capítulo II do Título III do CDC e a Lei das Ações Civis Públicas formam, em conjunto, um microssistema próprio do processo coletivo, seja qual for a sua natureza, consumerista, ambiental ou administrativa.

Assim, com o propósito também de contornar a impropriedade técnico-processual cometida pelo art. 16 da LACP, a questão relativa ao alcance da sentença proferida em ações coletivas deve ser equacionada de modo a harmonizar os vários dispositivos aplicáveis ao tema.

Nessa linha, o alcance da sentença proferida em ação civil pública deve levar em consideração o que dispõe o Código de Defesa do Consumidor acerca da extensão do dano e da qualidade dos interesses metaindividuais postos em juízo.

O norte, portanto, deve ser o que dispõem os arts. 93 e 103 do CDC.

Finalmente, embora haja doutrina e precedentes que, para contornar o art. 16 da LACP, aduzam que o dispositivo somente possui operância quando se tratar de direitos difusos ou coletivos em sentido estrito, sendo inaplicável a direitos individuais homogêneos, o fato é que - para os direitos difusos e coletivos em sentido estrito - é que está a maior dificuldade de aplicação da norma, porquanto supõem, por definição, titulares indeterminados ou indetermináveis, ligados por circunstâncias de fato, sendo imprópria a cisão dos efeitos da sentença, em razão de alegada limitação territorial.

Esse é, por exemplo, o magistério de Teori Albino Zavascki, citado por Mancuso, para quem, no caso de direitos difusos e coletivos stricto sensu:

(...) não há como cindir territorialmente a qualidade da sentença ou da relação jurídica nela certificada. Observe-se que, tratando-se de direitos transindividuais, a relação jurídica litigiosa, embora com pluralidade indeterminada de sujeitos no pólo ativo, é única e indivisível). Como tal, a limitação territorial da coisa julgada é, na prática, ineficaz em relação a ela. Não se pode circunscrever territorialmente (circunstância do mundo físico) o juízo de certeza sobre a existência ou a inexistência ou o mundo de ser de relação jurídica (que é fenômeno do mundo dos pensamentos). (Apud MANCUSO, Rodolfo de Camargo, Op. Cit., p. 320).

A conclusão da Corte Especial do Superior Tribunal de Justiça vai ao encontro com os argumentos sustentados na presente pesquisa de modo a serem ampliados os limites subjetivos da coisa julgada no âmbito da ação civil pública.

\section{CONSIDERAÇÕES FINAIS}

A partir da presente pesquisa, pode-se concluir:

1. Os limites subjetivos da coisa julgada na ação civil pública adquiriram tratamento diferenciado a partir da edição da Lei da Ação Civil Pública e do Código de Defesa do Consumidor.

2. Entretanto a amplitude dada pelo artigo 103 do Código de Defesa do Consumidor ao artigo 16 da Lei da Ação Civil Pública foi restringida com a edição da Lei 9.494/97, que vinculou os limites 
subjetivos da coisa julgada nessa hipótese à competência territorial do juiz prolator da decisão.

3. $O$ artigo 16 da LACP, ao restringir o alcance dos limites subjetivos da coisa julgada, reflete a inadequação da dogmática jurídica para resolver os problemas da pós-modernidade. Não é possível, no âmbito de uma economia globalizada, resolver-se o problema dos limites subjetivos da coisa julgada na ação civil pública a partir dos conceitos tradicionais utilizados no modelo liberal individualista. Assim, os conceitos aplicados à teoria geral do processo civil são inaplicáveis em sua grande maioria à ação civil pública.

4. O redimensionamento da concepção da dogmática jurídica e de sua respectiva função dificilmente será alcançado por meio de uma visão normativista de direito.

5. O Direito não pode ser visto como uma mera instrumentalidade formal. Assim, a hermenêutica jurídica se revela como uma das formas de des-velamento do real conteúdo das normas que compõem o ordenamento jurídico. Um dispositivo legal terá ou não eficácia a partir do processo de produção de sentido que exsurgirá do processo hermenêutico.

6. A hermenêutica jurídica não deve se restringir a uma mera reprodução de significados preestabelecidos. O processo hermenêutico deve basear-se em uma interpretação que dê novo sentido aos processos decisórios do direito. O Direito deve ser compreendido não como uma sucessão de normas com sentidos pré-constituídos, reclamando apenas que o intérprete hermeneuta lhes dê vida, e sim como norma que reclama um novo sentido.

7. Em se tratando de limites subjetivos da coisa julgada na ação civil pública, a incerteza do artigo 16 é significativa diante do texto constitucional. Não se pode interpretar tal dispositivo dissociado da Magna Carta, tendo em vista que a Constituição é um espaço garantidor das relações entre o Estado e a Sociedade.

8. A Constituição é o topos hermenêutico que conforma a interpretação jurídica do restante do sistema jurídico. Os princípios e as diretrizes constitucionais como valores fundamentais governam a Constituição, o regime e a ordem jurídica. Os princípios não são apenas a lei, mas o Direito em toda a sua extensão, substancialidade, plenitude e abrangência.

9. O respeito a um princípio é mais importante que a uma regra jurídica. Assim, a redação do artigo 16 da Lei da Ação Civil Pública, dada pela Lei 9494/97, deve ser interpretada à luz dos princípios e das diretrizes constitucionais.

10. O texto constitucional, em seu artigo 5. ${ }^{\circ}$, inciso XXXVI, em nenhum momento atrelou coisa julgada à competência.

11. A vinculação da coisa julgada à competência viola o princípio constitucional da isonomia.

12. A limitação territorial prevista no artigo 16 da Lei da Ação Civil Pública poderá deixar desprovida de tutela uma longa parcela da população brasileira, o que poderá conduzir à não efetividade de direitos fundamentais, circunstância essa que implicará o desrespeito a princípios constitucionais.

13. Se a limitação imposta pelo artigo 16 da LACP impedir a aplicação e a efetivação de direitos fundamentais, deverá ser dado um conteúdo mais amplo ao mesmo.

14. O Direito Processual Civil precisa se adaptar à condição jurídica pós-moderna, de forma que a dogmática jurídica cumpra a sua função social.

\section{REFERÊNCIAS}

BARBOSA MOREIRA, José Carlos. A legitimação para a defesa dos interesses difusos no direito brasileiro.

Revista AJURIS, Porto Alegre, n. 32, nov.1984, p. 81-92.

CAPPELletTI, Mauro. Acesso à Justiça. Revista do Ministério Público, n. 18, 1985, p. 8-26.

.Tutela dos interesses Difusos. Revista AJURIS, n. 33, mar. 1985.

CRUZ E TUCCI, José Rogério. 'Class action' e mandado de segurança coletivo, São Paulo: Saraiva, 1990. 
Limites subjetivos da eficácia da sentença e da coisa julgada civil. São Paulo: Editora Revista dos Tribunais, 2006.

DINAMARCO, Cândido Rangel. A reforma do Código de Processo Civil, 3. ed., São Paulo: Malheiros, 1996.

DWORKIN, Ronald. EI imperio de la justicia: de la teoria general del derecho, de las decisiones e interpretaciones de los jueces y de la integridad política y legal como clave de la teoría e práctica. Trad. Claudia Ferrari, 2. ed. Barcelona: Gedisa, 1992.

ECHANDÍA, Devis. Teoría general del proceso: aplicable a toda clase de procesos. 2. ed. Buenos Aires: Editorial Universidad, 1997.

FIGUEIREDO, Lúcia Valle. Direitos difusos e coletivos. São Paulo: Revista dos Tribunais,1989.

GADAMER, Hans-Georg. Verdad y metodo I: fundamentos de una hermenéutica filosofica. Trad. Ana Agud Aparicio y Rafael de Agapito. 6. ed. Salamanca: Sígueme, 1996.

GARCÍA-PELAYO, Manuel. Las transformaciones del Estado contemporáneo. 2. ed. Madrid: Alianza Universidad, 1996.

GRASSO, Eduardo. Gli Interessi della Collettività e I'azione Collettiva. Rivista di Diritto Processuale Civile, Padova: Cedam, n. 1, 1983, p. 24-56.

GRINOVER, Ada Pellegrini. A ação Civil Pública e a defesa dos interesses individuais homogêneos. Revista de Direito do Consumidor, n. 5, jan./mar. 1993, p. 206-229.

GRINOVER, Ada Pellegrini et alii. Código Brasileiro de Defesa do Consumidor: comentado pelos autores do anteprojeto. 9. ed. Rio de Janeiro: Forense Universitária, 2007.

GUERRA FILHO, Willis Santiago. Processo constitucional e direitos fundamentais. São Paulo, Celso Bastos, 1998.

MANCUSO, Rodolfo de Camargo. Interesses difusos: conceito e legitimação para agir. 4. ed. São Paulo: Revista dos Tribunais, 1997.

Coisa julgada, 'Collateral Estoppel 'e Eficácia Preclusiva 'secundum eventum litis' . Revista dos Tribunais, n. 608, jun. 1986. , p. 23-33.

Ação civil pública: em defesa do meio ambiente, do patrimônio cultural e dos consumidores. 11. ed. São Paulo: Revista dos Tribunais, 2009.

MORAIS, Jose Luis Bolzan de. Do direito social aos iteresses transindividuais: o Estado e o Direito na ordem contemporânea. Porto Alegre: Livraria do Advogado, 1996.

NERY JUNIOR, Nelson. Princípios do Processo Civil na Constituição Federal. 2. ed. São Paulo: Revista dos Tribunais, 1995.

OST, François. Entre Droit et Non Droit: I 'intérêt - Essai sur le fonsctions qu 'exerce la notion d 'intérêt en droit privé. Bruxelles: Facultés Universitaires Saint-Louis, 1990.

PORTANOVA, Rui. Princípios do Processo Civil. Porto Alegre: Livraria do Advogado, 1995.

PORTO, Sérgio Gilberto. Da tutela coletiva e do CPC. Revista AJURIS, n. 57, mar. p. 136-148.

STRECK, Lenio Luiz. Hermenêutica jurídica e(m) crise: uma exploração hermenêutica da construção do Direito. Porto Alegre: Livraria do Advogado, 1999.

VIGLIAR, José Marcelo Menezes. Ação civil pública. 3. ed. São Paulo: Atlas, 1999.

VIGORITI, Vincenzo. Interessi collettivi e processo - la legitimazione ad agire. Milano: Dott A. Giuffrè, 1979.

WATANABE et alii. Código Brasileiro de Defesa do Consumidor comentado pelos autores do anteprojeto. Rio de Janeiro: Forense, 1991. 